\title{
Microfiltration: Effect of channel diameter on limiting flux and serum protein removal ${ }^{1}$
}

\author{
E. E. Hurt, M. C. Adams, and D. M. Barbano² \\ Northeast Dairy Foods Research Center, Department of Food Science, Cornell University, Ithaca, NY 14853
}

\begin{abstract}
Our objective was to determine the limiting flux and serum protein (SP) removal at 8, 9 and $10 \%$ true protein (TP) in the retentate recirculation loop using 0.1- $\mu \mathrm{m}$ ceramic graded permeability (GP) microfiltration (MF) membranes with $3 \mathrm{~mm}$ channel diameters (CD). An additional objective was to compare the limiting flux and SP removal between $0.1-\mu \mathrm{m}$ ceramic GP membranes with $3 \mathrm{~mm} \mathrm{CD}$ and previous research using 4-mm CD membranes. The MF system was operated at $50^{\circ} \mathrm{C}$, using a diluted milk protein concentrate with $85 \%$ protein on a total solids basis (MPC85) as the MF feed. The limiting flux for the MF of diluted MPC85 was determined at 8, 9, and 10\% TP concentration in the recirculation loop. The experiment using the $3-\mathrm{mm}$ CD membranes was replicated 3 times for a total of 9 runs. On the morning of each run MPC85 was diluted with reverse osmosis water to a MF feed TP concentration of $5.4 \%$. In all runs the starting flux was 55 $\mathrm{kg} / \mathrm{m}^{2}$ per hour, the flux was then increased in steps until the limiting flux was reached. For the $3-\mathrm{mm}$ CD membranes, the limiting flux was $128 \pm 0.3,109 \pm$ 4 , and $97 \pm 0.5 \mathrm{~kg} / \mathrm{m}^{2}$ per hour at recirculation loop TP concentrations of $8.1 \pm 0.07,9.2 \pm 0.04$, and 10.2 $\pm 0.03 \%$, respectively. For the 3 -mm CD membranes, increasing the flux from the starting to the limiting flux decreased the SP removal factor from $0.72 \pm 0.02$ to $0.67 \pm 0.01$; however, no difference in SP removal factor among the target recirculation loop TP concentrations was detected. The limiting flux at each recirculation loop target TP concentration was lower for the 3- compared with the 4-mm CD membranes. The differences in limiting fluxes between the 3 - and 4-mm CD membranes were explained in part by the difference in cross-flow velocity $(5.5 \pm 0.03$ and $7.0 \pm 0.03 \mathrm{~m} / \mathrm{s}$ for the 3 - and 4-mm CD membranes, respectively). The
\end{abstract}

Received December 10, 2014.

Accepted February 23, 2015.

${ }^{1}$ Use of names, names of ingredients, and identification of specific models of equipment is for scientific clarity and does not constitute any endorsement of product by authors, Cornell University or the Northeast Dairy Foods Research Center.

${ }^{2}$ Corresponding author: dmb37@cornell.edu
SP removal factor was also lower for the 3 - compared with the 4-mm CD membranes, indicating that more membrane fouling may have occurred in the 3 - versus 4-mm CD membranes.

Key words: microfiltration, limiting flux, serum protein removal

\section{INTRODUCTION}

Microfiltration (MF) has been used to remove serum protein (SP) and other low molecular weight components (i.e., lactose and NPN) from skim milk (Fauquant et al., 1988; Zulewska et al., 2009) or a milk protein concentrate (MPC; Hurt et al., 2015b). As a feed material for MF, MPC will have had a large amount of lactose, soluble minerals, and NPN removed before MF compared with skim milk. The use of a diluted MPC as an MF feed would produce a micellar casein concentrate (MCC) with a lower lactose and NPN concentration compared with the use of skim milk as the MF feed. An MCC would have a low concentration of heat-labile components, such as SP and lactose, and may be suitable for the formulation of high-protein, shelf-stable beverages. Both the membranes used for MF and the operating conditions (including flux) could affect the MCC composition and the MF membrane area required to produce the MCC.

In MF there are 3 important fluxes: critical, limiting, and sustainable flux. The critical flux is the flux at which membrane fouling begins to occur (Bacchin et al., 2006). Below the critical flux a linear relationship exists between flux and increasing transmembrane pressure (TMP), and as flux exceeds the critical flux the membrane starts to foul and the relationship between flux and TMP is no longer linear. The limiting flux is the highest flux that can be achieved by increasing the TMP (Bacchin et al., 2006). The critical and limiting fluxes are shown in Figure 1. The third important flux is the sustainable flux. A sustainable flux is a flux that the system can operate at for extended periods of time, such as a production run (Bacchin et al., 2006). The sustainable flux would fall somewhere between the critical and limiting fluxes, where the rate of membrane fouling is low (Bacchin et al., 2006). 


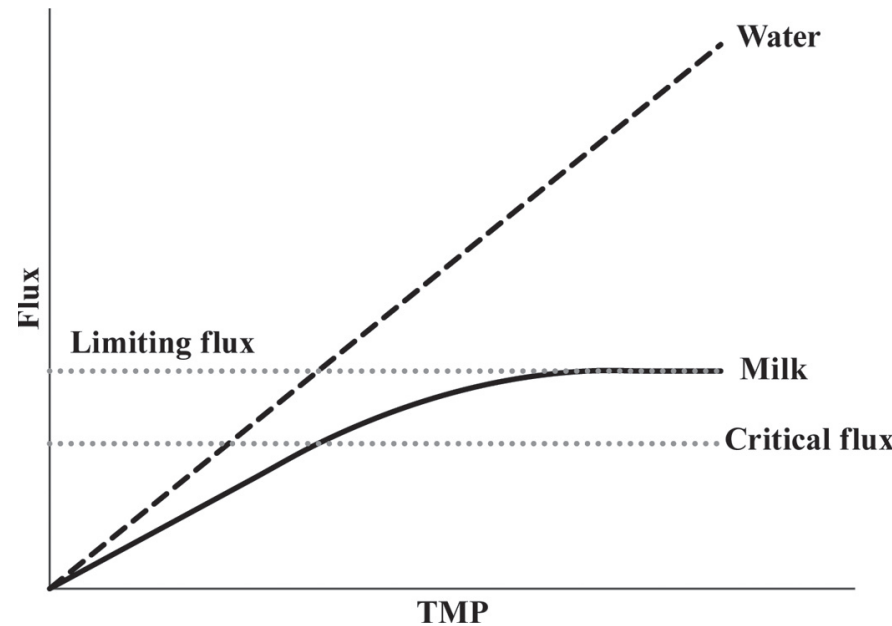

Figure 1. Limiting flux and critical flux on a graph of flux as a function of transmembrane pressure (TMP). Adapted from Bacchin et al. (2006) with permission.

The MF membranes used to produce an MCC could affect both the SP removal and the overall flux and performance of the MF system. Previous work has compared the flux and SP removal of ceramic versus polymeric membranes (Zulewska et al., 2009). In general, flux and SP removal are lower with polymeric membranes (Zulewska et al., 2009) than ceramic membranes. Different types of ceramic membranes have been used to MF milk. Ceramic membranes typically operate at high cross-flow velocities (2 to $6 \mathrm{~m} / \mathrm{s}$; Cheryan, 1998). A large longitudinal pressure drop $(\boldsymbol{\Delta} \mathbf{P})$ on the retentate side of the membrane is required to achieve high cross-flow velocities. A high cross-flow velocity results in a TMP at the inlet end of the membrane that is much larger than the TMP at the outlet end of the membrane, which could result in higher fluxes at the inlet end of the membrane and increased membrane fouling at the inlet end.

There have been several methods developed to create a uniform flux along the length of ceramic membranes. In the uniform transmembrane pressure (UTP) system, a permeate recirculation pump is used to produce co-current flow of permeate in parallel to the retentate, which produces a gradient of back pressure on the permeate side of the membrane; this creates a pressure drop on the permeate side of the membrane that matches the pressure drop on the retentate side of the membrane (Holm et al., 1990). Another method is to manufacture the membranes with a resistance gradient so that the flux is constant along the length of the membrane even with a large $\Delta \mathrm{P}$. Two commercially available ceramic membranes with a resistance gradient are the graded permeability (GP) membranes (Pall Corp., Cortland, NY), which have the resistance gradient on the outside of the support layer (Garcera and Toujas, 2002), and Isoflux membranes (TAMI, Nyons, France), which has the resistance gradient built into the separating layer of the membrane (Grangeon et al., 2002).

Zulewska et al. (2009) reported that in a 1-stage, $3 \times$ MF process, $64 \%$ of the SP was removed in a UTP system $[0.1 \mu \mathrm{m}, 4-\mathrm{mm}$ channel diameter (CD)] and $61 \%$ of the SP was removed using GP membranes $(0.1 \mu \mathrm{m}$, $4 \mathrm{~mm} \mathrm{CD}$ ). Isoflux membranes have been reported to remove less SP (40\%) than the UTP or GP membranes (Adams and Barbano, 2013). Whereas SP removal was similar for the UTP and GP systems, the GP system does not require a permeate recirculation pump, and a system with GP membranes would have both a lower fixed and operating cost.

Graded permeability membranes come in several configurations; GP membranes are available with both 3 and $4 \mathrm{~mm} \mathrm{CD}$ (Sondhi et al., 2003). The GP membranes are designed to operate at a specific $\Delta \mathrm{P}$ (Garcera and Toujas, 2002). The 3-mm CD membranes have a greater surface area $(46 \%)$ per stick compared with 4-mm CD membranes. The limiting flux and SP removal factor for 4-mm CD membranes at 8, 9, and $10 \%$ target true protein (TP) concentrations in the recirculation loop were reported by Hurt et al. (2015b); however, little information is available on the performance of $3-\mathrm{mm}$ CD membranes for the production of an MCC using diluted MPC as a feed material.

Limiting flux and SP removal could be a function of the MF membrane CD. The limiting flux is a function of the back transport of molecules away from the surface of the membrane (Belfort et al., 1994). Several factors could affect the back transport of molecules, including viscosity, particle size, concentration, and shear rate at the surface of the membrane (Belfort et al., 1994). From the literature it is not clear what effect CD will have on membrane fouling and, thus, limiting flux or SP removal factor. In a review by Belfort et al. (1994), 4 models for the prediction of limiting flux were presented. Channel diameter does not appear explicitly in any of the models, but in all of the models increasing the shear rate at the wall was predicted to increase limiting flux.

The shear rate at the wall could be a function of CD. Reynold's number is defined in Equation 1:

$\frac{\begin{array}{r}\text { Reynold's number }= \\ \text { density }\left(\frac{\mathrm{kg}}{\mathrm{m}^{3}}\right) \times \text { cross-flow velocity }\left(\frac{\mathrm{m}}{\mathrm{s}}\right) \times \text { channel diameter }(\mathrm{m})\end{array}}{\text { retentate viscosity }(\mathrm{Pa} \cdot \mathrm{s})}$.

For laminar flow [Reynold's numbers $<2,100$ (Denn, 1980)], shear rate at the wall is proportional to cross- 
flow velocity and inversely proportional to CD (Belfort et al., 1994), and at a constant cross-flow velocity decreasing the CD would increase the shear rate and be expected to increase the limiting flux. However, for tubular ceramic membranes, the flow is usually turbulent and the cross-flow velocity is in the range of 2 to $6 \mathrm{~m} / \mathrm{s}$. Hurt et al. (2015b) reported that for 4-mm CD ceramic GP membranes the Reynold's numbers were greater than 15,000, indicating turbulent flow. There is not a simple relationship for shear rate as a function of cross-flow velocity and CD for turbulent flow. If decreasing the CD increases the shear rate at the wall, according to Belfort et al. (1994), the limiting flux should increase.

In contrast, Samuelsson et al. (1997) found that limiting flux was a linear function of the Reynold's number, as did Hurt et al. (2015b), which predicts that at a constant cross-flow velocity decreasing the CD would decrease the limiting flux. However, in both Samuelsson et al. (1997) and Hurt et al. (2015b), CD was a constant, so the linear relationship between limiting flux and Reynold's number has not been validated for membranes with different CD. An additional complication arising from the use of GP membranes is that when operating at a constant $\Delta \mathrm{P}$, cross-flow velocity will depend on the $\mathrm{CD}$, viscosity, and density (e.g., protein concentration) of the retentate (Denn, 1980). Our objective was to determine the limiting flux and $\mathrm{SP}$ removal at 8,9 , and $10 \% \mathrm{TP}$ in the recirculation loop using $0.1-\mu \mathrm{m}$ ceramic GP membranes with $3-\mathrm{mm}$ CD. An additional objective was to compare the limiting flux and SP removal between $0.1-\mu \mathrm{m}$ ceramic GP membranes with 3 and $4 \mathrm{~mm} \mathrm{CD}$.

\section{MATERIALS AND METHODS}

\section{Experimental Design and Statistical Analysis}

The limiting flux for the MF of diluted MPC with $85 \%$ TP as a percentage of TS (MPC85) was determined at $3 \mathrm{TP}$ concentrations in the recirculation loop $(8,9$, and $10 \%$ ) on $0.1-\mu \mathrm{m}$ GP membranes with $3 \mathrm{~mm} \mathrm{CD}$. The experiment was replicated 3 times. On the morning of each processing run, MPC85 was diluted with reverse osmosis water to a MF feed TP concentration of $5.4 \%$. In all processing runs the starting flux was $55 \mathrm{~kg} / \mathrm{m}^{2}$ per hour and the flux was increased in steps until the limiting flux was reached. The minimum flux increase was $10 \mathrm{~kg} / \mathrm{m}^{2}$ per hour. For the $3-\mathrm{mm}$ CD membranes, a different batch of MPC85 was used for each replicate. In a separate paper (Hurt et al., 2015b), the limiting flux and SP removal at 8, 9, and $10 \%$ TP using 4 -mm $\mathrm{CD}$ membranes $(0.1-\mu \mathrm{m}$ ceramic GP) with a $\Delta \mathrm{P}$ of 220
$\mathrm{kPa}$ was reported. The experiments performed using the 4-mm CD membranes were completed first with different batches of MPC85. The performance of the 3 -mm CD membranes is compared with the previously reported performance of the $4-\mathrm{mm} \mathrm{CD}$ membranes in the current paper.

All data were analyzed by ANOVA using the Proc GLM (general linear model) procedure of SAS (SAS version 8.02, SAS Institute Inc., Cary, NC). For the 3-mm CD membranes, the data was analyzed at the starting and limiting flux using a GLM where the dependent variable $=$ target $\mathrm{TP}+$ error. The target $\mathrm{TP}$ concentration in the recirculation loop was a class variable with 3 levels: 8,9 , or $10 \%$.

To determine the effect of CD, recirculation loop TP concentration (target TP), and flux had on membrane performance (i.e., measured flux, cross-flow velocity and SP removal factor), a split-plot model was used with CD and target TP as the whole plot terms and flux with interactions as the sub plot terms. Flux was a categorical variable (starting flux or limiting flux). The GLM was: dependent variable $=\mathrm{CD}+$ target $\mathrm{TP}$ $+\mathrm{CD} \times$ target $\mathrm{TP}+$ flux + target $\mathrm{TP} \times$ flux $+\mathrm{CD}$ $\times$ flux $+\mathrm{CD} \times$ target $\mathrm{TP} \times$ flux + error. No separate term for replicate was used in the model because all 3 replicates on the 4-mm CD membranes were performed using different batches of MPC85 at a different time than the 3 replicates on the $3-\mathrm{mm} \mathrm{CD}$ membranes; thus, no relationship occurred between replicates of the same number among the 2 experiments. The type III mean squares for $\mathrm{CD} \times$ target $\mathrm{TP}$ was used as the denominator in the F-test to test the significance of the whole-plot terms (CD, target TP). The type III mean square error for the model was used as the denominator in the F-test to test the significance of the sub plot terms.

\section{Preparation of MF Feed}

For MF processing with the 3-mm CD membranes, the MF feed was a fresh liquid MPC85 with $86 \pm$ $0.2 \%$ TP on a TS basis, provided by O-AT-KA Milk Products Cooperative Inc. (Batavia, NY). The MPC85 was produced by UF (at 13 to $15^{\circ} \mathrm{C}$ ) of pasteurized $\left(73^{\circ} \mathrm{C}\right.$ for $\left.20 \mathrm{~s}\right)$ skim milk. The liquid MPC85 at approximately $12.35 \pm 0.07 \%$ TP determined using an infrared spectrophotometer (IR; Milkoscan, Foss, Hillerød, Denmark) was stored at $<4^{\circ} \mathrm{C}$ until use. On each day, MPC85 $\left(277 \pm 12 \mathrm{~kg}\right.$ at $\left.4^{\circ} \mathrm{C}\right)$ was diluted to $5.4 \%$ $\mathrm{TP}$, as determined with by IR, with hot $\left(70^{\circ} \mathrm{C}\right)$ reverse osmosis water $(322 \pm 12 \mathrm{~kg})$ in a separate jacketed MF product feed tank. The diluted MPC85 was heated to a final temperature of $50^{\circ} \mathrm{C}$ in the $\mathrm{MF}$ product feed tank. 


\section{MF System}

A 0.1- $\mu$ m ceramic GP Membralox module with $3 \mathrm{~mm}$ CD $(7$ sticks with 37 channels per stick and a membrane area of $2.5 \mathrm{~m}^{2}$; EP3730GL0.1 $\mu \mathrm{A}$, Alumina, Pall Corp.) was used. The membranes with $4 \mathrm{~mm}$ CD had 7 sticks with 19 channels per stick for a membrane area of

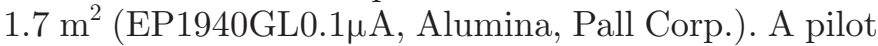
MF system (model CF 1000, Pall Corp.) as described in Hurt et al. (2015b) was used.

The flux, concentration factor $(\mathbf{C F}), \Delta \mathrm{P}$, and outlet pressure on the retentate side (Pro) were controlled during the processing run. The flux was controlled by opening and closing the permeate removal valve. The $\mathrm{CF}$ was controlled by opening and closing the retentate removal valve. The $\Delta \mathrm{P}$ was controlled to $220 \mathrm{kPa}$ by increasing or decreasing the recirculation pump speed, and the retentate outlet pressure (Pro) was controlled by modifying the feed pump speed. Transmembrane pressure was calculated as the average of the pressure at the retentate inlet (Pri) and outlet end (Pro) of the membrane on the retentate side minus the permeate pressure at the outlet (Ppo) end of the membrane $[($ Pro + Pri $) / 2-$ Ppo $]$. The recirculation rate was measured with an in-line flow meter (Hurt et al., 2015b) and cross-flow velocity was calculated by dividing the recirculation rate by the cross-sectional area $(0.00167$ $\mathrm{m}^{2}$ for the $4-\mathrm{mm} \mathrm{CD}$ membranes and $0.00183 \mathrm{~m}^{2}$ for the 3-mm CD membranes).

\section{MF Operation}

On each day of processing, the MF system was rinsed as described in Hurt et al. (2015b). Next, the clean water flux was measured at $50^{\circ} \mathrm{C}$ by turning off the recirculation pump (with the feed pump running), closing the retentate removal valve, and opening the permeate removal valve to $95 \%$ of fully open. The average clean water flux for the 3 -mm membranes was $280 \pm 4 \mathrm{~kg} /$ $\mathrm{m}^{2}$ per hour, which was less than the clean water flux for $4-\mathrm{mm}$ CD membranes $\left(363 \pm 1 \mathrm{~kg} / \mathrm{m}^{2}\right.$ per hour) reported by Hurt et al. (2015b). The difference in clean water flux with $\mathrm{CD}$ was, at least in part, due to the difference in membrane area and membrane resistance. If the membranes contributed no resistance to fluid flow, in the module a maximum permeate removal rate would be achieved under the conditions at which the clean water flux was measured. The flux (removal rate divided by membrane area) would be lower (by about $46 \%$ ) for the $3-\mathrm{mm}$ membranes because of the larger surface area of the 3- than the 4-mm membranes. The clean water flux on the 3-mm CD membranes was only about $30 \%$ less than on the 4 -mm membranes. This was probably because the 3-mm CD membranes have more membrane area per stick and thus less support material and resistance to flow compared with the 4-mm CD membranes.

Start-up. The system was started-up as described in Hurt et al. (2015b); the pressure at the outlet end of the membrane on the retentate side was set to $230 \mathrm{kPa}$ and the $\Delta \mathrm{P}$ was set to $220 \mathrm{kPa}$. The flux was set to 55 $\mathrm{kg} / \mathrm{m}^{2}$ per hour and the $\mathrm{CF}$ set to achieve the target recirculation loop protein concentrations. To flush the MF system, approximately $298 \pm 13 \mathrm{~kg}$ of permeate and retentate were collected, weighed, and discarded while feeding the system with diluted MPC85 at 5.4\% TP. Once the concentration of TP in the retentate in the recirculation loop was within $10 \%$ of the target $\mathrm{TP}$ concentration as determined by IR analysis of the retentate, the retentate and permeate were recycled to the MF product feed tank. The start-up took about 60 min.

Determination of Limiting Flux. After the retentate and permeate were recycled to the MF product feed tank, the system was operated at a flux of $55 \mathrm{~kg} /$ $\mathrm{m}^{2}$ per hour for $1 \mathrm{~h}$. Permeate and retentate removal rates were measured by weight every $15 \mathrm{~min}$. Pressures, temperature, and the recirculation rate were also recorded every $15 \mathrm{~min}$. After $1 \mathrm{~h}$ at $55 \mathrm{~kg} / \mathrm{m}^{2}$ per hour, the flux was increased. The flux was increased in steps (the minimum flux step was $10 \mathrm{~kg} / \mathrm{m}^{2}$ per hour) with a 1-h stabilization period after each increase. At some point the target flux could not be achieved and further increasing the TMP did not produce an increase in flux. The limiting flux was taken as the last flux that the system was able to operate at stably (constant TMP) for $1 \mathrm{~h}$.

Samples of retentate and permeate $(65 \mathrm{~mL}$ per container) were taken after the 1-h stabilization period at each flux and frozen (in an insulted cooler using dry ice) for later chemical analysis. The TP concentration of the retentate and permeates was monitored during the run every 15 min by IR analysis. Based on the results from the IR, the $\mathrm{CF}$ was adjusted to maintain the target TP concentration. Immediately after each run, the MF system was cleaned as described in Hurt et al. (2015b).

\section{Chemical Analyses}

A sample of the MF feed (diluted MPC85) was taken before each run and samples of the permeate and retentate were taken at each flux. The samples were frozen $\left(-40^{\circ} \mathrm{C}\right)$ until analysis. The MF feed (diluted MPC85) was analyzed for TS, fat, and lactose using forced-air oven drying (AOAC International, 2000; 
method 990.20; 33.2.44), ether extraction (AOAC International, 2000; method 989.05; 33.2.26), and enzymatic lactose (AOAC International, 2000; method 984.15; 33.2.67, Lynch et al., 2007), respectively. The diluted MPC85, retentates, and permeates were analyzed for total nitrogen (TN) and NPN by Kjeldahl (method 991.20, 33.2.11; and method 991.21, 33.2.12, respectively; AOAC International, 2000). Noncasein nitrogen (NCN) content of the diluted MPC85 was determined using Kjeldahl (AOAC International, 2000; method $998.05 ; 33.2 .64$ ), modified by using $5.5 \mathrm{~mL}$ of acetic acid $(10 \% \mathrm{vol} / \mathrm{vol})$ and $5.5 \mathrm{~mL}$ of sodium acetate $(1 \mathrm{~N})$, instead of $1 \mathrm{~mL}$ of each, to ensure that a final filtrate $\mathrm{pH}$ of less than 4.6 was achieved and that all of the casein was precipitated. Total protein was calculated by subtracting NPN from TN and multiplying by 6.38 ; casein was calculated by subtracting the NCN from TN and multiplying by 6.38 ; and $\mathrm{SP}$ content was calculated by subtracting NPN from NCN and multiplying by 6.38 .

Viscosity of the retentates was measured at each flux. The viscosity was measured at $50^{\circ} \mathrm{C}$ using a Brookfield viscometer (model LV-DV2T) with a UL adapter for low-viscosity fluids (Brookfield Engineering Laboratories Inc., Middleboro, MA). A water bath was heated to $50^{\circ} \mathrm{C}$ and this water was recirculated through the jacketed sample cup using a peristaltic pump. The retentate samples were heated in a water bath at $50^{\circ} \mathrm{C}$, and then approximately $16 \mathrm{~mL}$ was placed in the sample cup. The viscosity was measured at $60 \mathrm{rpm}$ (shear rate of 73 $\mathrm{s}^{-1}$ ) for $50 \mathrm{~s}$. The spindle rotation speed was chosen to provide a torque measurement between 10 and $90 \%$ of the full scale of viscometer. The recorded viscosity was the average viscosity (measured in $\mathrm{Pa} \cdot \mathrm{s}$ ) during the last $30 \mathrm{~s}$ of the measurement.

\section{Calculation of the SP Removal Factor}

The SP removal factor was the ratio of SP removed in the permeate to the theoretical SP removal. An SP removal factor of 1 would mean that the membrane was not rejecting any SP. Theoretical SP removal (in kilograms) was equal to the mass of permeate multiplied by the concentration of SP in the permeate portion of the MF feed. The concentration of SP in the permeate portion of the MF feed was the mass of SP in the feed divided by the mass of feed less the mass of $\mathrm{CN}$ in the feed. The actual SP removed in the permeate (in kilograms) was the mass of permeate multiplied by the concentration of TP in the permeate. It was assumed that all of the TP in the permeate was SP. Because mass of permeate appears in both the numerator and denominator the SP removal factor was independent of permeate mass.

\section{RESULTS}

\section{3-mm CD Membranes}

MF Feed Composition. The composition of the MF feed for the 3-mm CD membranes at the 3 target recirculation loop TP concentrations is shown in Table 1. The MPC85 was diluted based on IR analysis results to achieve the same TP concentration in the diluted MPC for all 3 target recirculation loop TP concentrations. No differences in the composition of the MF feed among the 8, 9, and $10 \%$ target TP concentrations were detected. Hurt et al. (2015b) reported that the same result was achieved in an experiment with 4-mm membranes.

Retentate and Permeate Composition. The CF was controlled during each processing run to achieve

Table 1. Mean $(\mathrm{n}=3)$ composition of the diluted milk protein concentrate used as the microfiltration (MF) feed for the 3-mm channel diameter (CD) membranes all values are given in percent by weight for 8,9 , and $10 \%$ recirculation loop target true protein (TP) concentrations and the mean $(\mathrm{n}=9) \mathrm{MF}$ feed composition on the 3 - and 4-mm CD membranes ${ }^{1}$

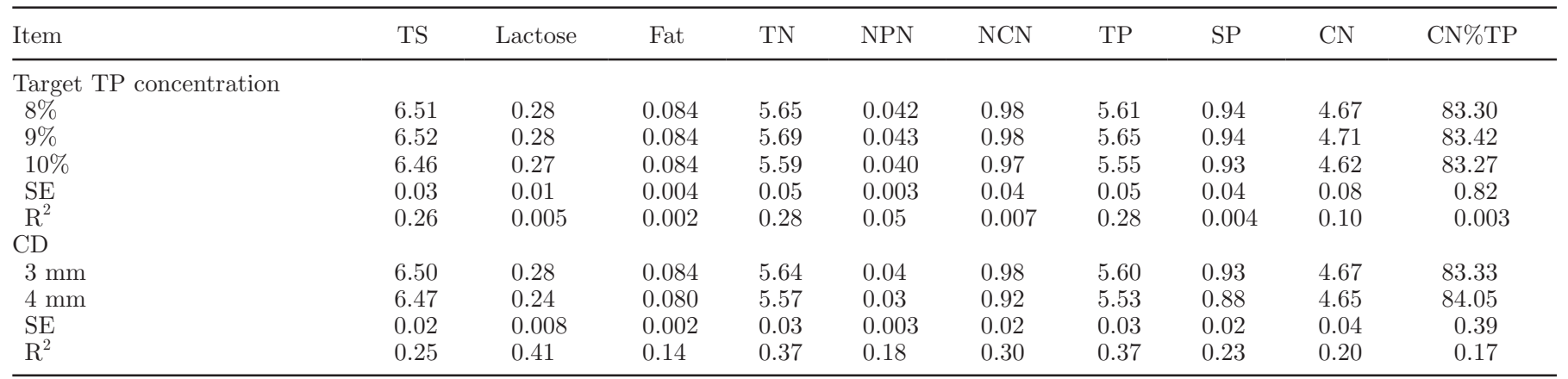

Means in the same column within target TP or CD do not differ $(P>0.05)$.

${ }^{1} \mathrm{TS}=$ anhydrous lactose $\mathrm{TN}=$ total nitrogen $\times 6.38 ; \mathrm{NPN}=$ nonprotein nitrogen $\times 6.38 ; \mathrm{NCN}=$ noncasein nitrogen $\times 6.38 ; \mathrm{TP}=$ true protein $(\mathrm{TN}-\mathrm{NPN}) ; \mathrm{SP}=$ serum protein $(\mathrm{NCN}-\mathrm{NPN}) ; \mathrm{CN}=(\mathrm{TN}-\mathrm{NCN}) ; \mathrm{CN} \% \mathrm{TP}=100 \times \mathrm{CN} / \mathrm{TP}$. 
the target recirculation loop $\mathrm{TP}$ concentration. The average retentate $\mathrm{TN}, \mathrm{NPN}$, and $\mathrm{TP}$ at the starting and limiting flux are shown in Table 2. The TN and $\mathrm{TP}$ concentrations in the retentate in the recirculation loop were different, as expected, among the 3 target TP concentrations $(P<0.05)$ at both the starting and limiting flux. The TN, NPN, and TP concentrations in the permeates are shown in Table 2. No difference in TN, TP, or NPN concentration in the permeate was detected $(P>0.05)$ among the 3 target recirculation loop TP concentrations at either the starting or limiting flux.

Microfiltration Process Parameters. The measured flux, $\Delta \mathrm{P}$, cross-flow velocity, and TMP are shown in Table 3. The MF system was operated to maintain a constant $\Delta \mathrm{P}$. As shown in Table 3 , no difference in $\Delta \mathrm{P}$ among the 3 target TP concentrations was detected at either the starting or limiting flux. Because the system was operated at a constant $\Delta \mathrm{P}$, the cross-flow velocity decreased $(P<0.05)$ as the TP concentration in the recirculation loop increased at both the starting and limiting flux (Table 3). Cross-flow velocity was also found to decrease as recirculation loop TP concentration increased when 4-mm CD membranes were operated at a $\Delta \mathrm{P}$ of $220 \mathrm{kPa}$ (Hurt et al. 2015b).

As shown in Table 3, no differences in the starting flux of $55 \mathrm{~kg} / \mathrm{m}^{2}$ per hour among the target recirculation loop TP concentrations were detected; however, TMP increased $(P<0.05)$ with increasing recirculation loop TP concentration at the starting flux. This may indicate that at the starting flux there was some resistance to permeate flow through the membrane that depended on the recirculation loop TP concentration. This is in contrast to what was found with 4-mm CD membranes, where no difference in TMP at the starting flux was detected among the 3 target TP concentrations (Hurt et al., 2015b). At the limiting flux (which depended on the recirculation loop TP concentration), no difference in TMP between the target recirculation loop TP concentrations was detected $(P>0.05)$ for the 3-mm CD membranes, but overall TMP was much higher at the limiting than at the starting flux. This is similar to the 4-mm CD membranes, where no difference in the TMP at the limiting flux was detected among target TP concentrations (Hurt et al., 2015b).

Limiting Flux and SP Removal Factor. The limiting flux decreased as the TP concentration in the recirculation loop increased, as shown in Table 3. The limiting flux will depend on the balance between transport of molecules toward the membrane due to flux and the back transport of molecules away from the surface of the membrane due to turbulent flow created by the high cross-flow velocity of the retentate. The back transport of $\mathrm{CN}$ away from the membrane is predicted

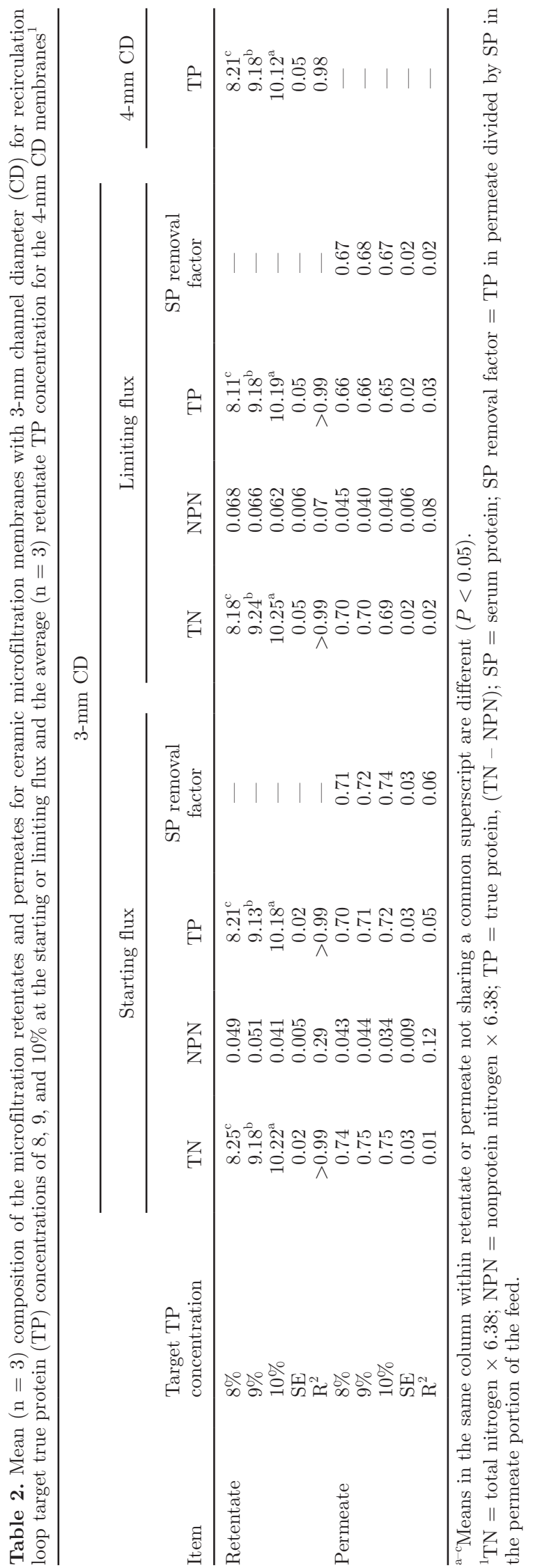


Table 3. Mean $(n=3)$ longitudinal pressure drop $(\Delta P)$, cross-flow velocity, and transmembrane pressure (TMP) at the starting flux of $55 \mathrm{~kg} / \mathrm{m}^{2}$ per hour and limiting flux for the $3-\mathrm{mm}$ channel diameter (CD) membranes at 8,9 , and $10 \%$ target true protein (TP) in the recirculation loop

\begin{tabular}{llcccc}
\hline Item & $\begin{array}{l}\text { Target TP } \\
\text { concentration }\end{array}$ & $\begin{array}{c}\text { Flux } \\
\left(\mathrm{kg} / \mathrm{m}^{2} \text { per hour }\right)\end{array}$ & $\begin{array}{c}\Delta \mathrm{P} \\
(\mathrm{kPa})\end{array}$ & $\begin{array}{c}\text { Cross-flow velocity } \\
(\mathrm{m} / \mathrm{s})\end{array}$ & $\begin{array}{c}\text { TMP } \\
(\mathrm{kPa})\end{array}$ \\
\hline Starting flux & $8 \%$ & 54.78 & 220 & $5.57^{\mathrm{a}}$ & $75.05^{\mathrm{b}}$ \\
& $9 \%$ & 55.80 & 220 & $5.50^{\mathrm{b}}$ & $78.40^{\mathrm{ab}}$ \\
& $10 \%$ & 54.70 & 220 & $5.40^{\mathrm{c}}$ & $84.81^{\mathrm{a}}$ \\
& $\mathrm{SE}$ & 0.47 & 0.14 & 0.007 & 1.50 \\
Limiting flux & $\mathrm{R}^{2}$ & 0.36 & 0.13 & 0.98 & 0.78 \\
& $8 \%$ & $128^{\mathrm{a}}$ & 220 & $5.57^{\mathrm{a}}$ & 228.77 \\
& $9 \%$ & $109^{\mathrm{b}}$ & 220 & $5.46^{\mathrm{b}}$ & 217.14 \\
& $10 \%$ & $97^{\mathrm{c}}$ & 220 & $5.38^{\mathrm{c}}$ & 250.58 \\
& $\mathrm{SE}$ & 2.10 & 0.17 & 0.006 & 16.25 \\
& $\mathrm{R}^{2}$ & 0.95 & 0.02 & 0.99 & 0.27 \\
\hline
\end{tabular}

${ }^{\mathrm{a}-\mathrm{c}}$ Means in the same column within starting flux or limiting flux not sharing a common superscript are different at either the starting or limiting flux $(P<0.05)$.

to increase with increasing cross-flow velocity and decrease with increasing retentate viscosity (Belfort et al., 1994). The dependence of limiting flux on TP concentration in the retentate (Table 3 ) is consistent with the back transport away from the membrane being dependent on the cross-flow velocity (which decreased as $\mathrm{TP}$ concentration increased) and the TP concentration (and viscosity) in the recirculation loop.

The SP removal factors are shown in Table 2. No differences $(P>0.05)$ in the SP removal factor among target TP concentrations at either the starting or limiting fluxes were detected. There were differences $(P<$ $0.05)$ in TMP required to achieve the starting flux at the different target recirculation loop TP concentrations (Table 3), indicating a resistance that depended on the recirculation loop TP concentration, but this did not appear to affect the rejection characteristics of the membrane (Table 2). No differences $(P>0.05)$ in SP removal factors at the limiting flux were detected for the 3 recirculation loop TP concentrations, indicating that the extent of membrane fouling that affected the rejection characteristics of the membrane were similar for all target TP concentrations at the limiting flux with 3 -mm membranes.

\section{Comparison of 3- and 4-mm CD Membranes}

MF Feed Composition. The average $(\mathrm{n}=9) \mathrm{MF}$ feed compositions (diluted MPC 85) for the 3- and 4-mm CD membranes are shown in Table 1 . The 9 processing runs on the 4-mm CD membranes were performed in a previous month, and the batches of MPC85 used were different from the batches of MPC85 used for the 3-mm CD membranes. The dilution of MPC85 concentrate with water was controlled using an infrared milk analyzer in attempt to achieve the same starting composition at all times. No difference among the
MF feed compositions (i.e., TP, SP, $\mathrm{CN}$, and $\mathrm{CN}$ as a percentage of TP) for the 3 - and 4-mm CD membranes was detected $(P>0.05)$.

Retentate TP Concentration. As presented herein for the 3-mm CD membranes and as reported by Hurt et al. (2015b) for the 4-mm CD membranes, the limiting flux depended on the TP concentration in the recirculation loop. The target recirculation loop TP concentrations were the same for the work with the 3- and 4-mm CD membranes (i.e., 8, 9, and 10\%). The measured TP concentrations in the recirculation loop for the 4-mm CD membranes are shown in Table 2. No difference $(P>0.05)$ in recirculation loop TP concentrations (Table 2) between the 3 - and 4-mm CD membranes was detected (Table 4). Additionally, no influence of flux on retentate TP concentration was detected $(P>0.05)$, indicating that the recirculation loop TP concentration was well controlled during processing as flux was increased.

Processing Parameters. For both the 3- and 4-mm $\mathrm{CD}$ membranes, the $\Delta \mathrm{P}$ was set to $220 \mathrm{kPa}$. As shown in Table $4, \Delta \mathrm{P}$ did not depend on target recirculation loop TP concentration, CD, or flux. Because the system was operated at a constant $\Delta \mathrm{P}$, the cross-flow velocity depended on both the membrane CD $(P<0.05$; Table 4) and recirculation loop TP concentration $(P<0.05$; Table 4), as shown in Figure 2. The retentate cross-flow velocity was much lower $(P<0.05)$ for 3 - than $4-\mathrm{mm}$ $\mathrm{CD}$ membranes (about 5.5 vs., $7.0 \mathrm{~m} / \mathrm{s}$, respectively). Lower cross-flow velocity may result in more membrane fouling and reduced passage of SP through the MF membrane. The membrane $\mathrm{CD}$ had a much larger effect on cross-flow velocity than differences in recirculation loop TP concentration, as shown in Figure 2, and the higher type III sum of squares for the CD model term than target TP (Table 4). The cross-flow velocity tended to decrease as the run progressed from starting 
Table 4. Analysis of variance df, type III sum of squares (SS) with retentate true protein (TP) concentration, measured flux, longitudinal pressure drop $(\Delta \mathrm{P})$, cross-flow velocity, average transmembrane pressure (TMP), and serum protein removal factor as the dependent variables, for the 3 - and 4-mm channel diameter (CD) membranes at target TP recirculation loop concentrations of 8,9 , and $10 \%$

\begin{tabular}{|c|c|c|c|c|c|c|c|}
\hline & & $\begin{array}{l}\text { Retentate TP } \\
\text { concentration }\end{array}$ & $\begin{array}{l}\text { Measured } \\
\text { flux }\end{array}$ & $\Delta \mathrm{P}$ & $\begin{array}{l}\text { Cross-flow } \\
\text { velocity }\end{array}$ & TMP & $\begin{array}{l}\text { Serum protein } \\
\text { removal factor }\end{array}$ \\
\hline Model term & $\mathrm{df}$ & SS & SS & SS & SS & SS & SS \\
\hline \multicolumn{8}{|l|}{ Whole plot } \\
\hline $\mathrm{CD}$ & 1 & $<0.001$ & $1,188.13^{*}$ & NS & $20.80^{*}$ & 6,817 & $0.054^{*}$ \\
\hline Target TP & 2 & $23.33^{*}$ & $1,879.74^{*}$ & NS & $0.197^{*}$ & 436.85 & 0.0009 \\
\hline Flux & 1 & - & $41,722.4^{*}$ & NS & $0.007^{*}$ & $171,768^{*}$ & $0.0235^{*}$ \\
\hline Flux $\times$ CD & 1 & - & $1,268.00^{*}$ & NS & — & $1,918^{*}$ & — \\
\hline Flux $\times$ Target TP & 2 & - & $1,675.63^{*}$ & NS & $0.002 *$ & - & - \\
\hline Flux $\times \mathrm{CD} \times$ Target $\mathrm{TP}$ & 2 & - & - & NS & - & - & - \\
\hline Model df & & 5 & 9 & - & 8 & 7 & 6 \\
\hline Error df & & 30 & 26 & - & 27 & 28 & 29 \\
\hline $\mathrm{R}^{2}$ & & 0.99 & $>0.99$ & 0.39 & $>0.99$ & 0.96 & 0.54 \\
\hline
\end{tabular}

${ }^{1}$ Used as error term for whole-plot variables: CD and target TP.

$* P<0.05$.

to limiting flux, but the magnitude was small $(0.03 \pm$ $0.005 \mathrm{~m} / \mathrm{s}$ ), and explains the significant flux term in Table 4.

A trend was observed for TMP to depend $(\mathrm{P}=0.06)$ on $\mathrm{CD}$, and there was an effect $(P<0.05)$ of flux and a flux by CD interaction (TMP pressure increased as flux was increased). The TMP at the starting flux, which was $55 \mathrm{~kg} / \mathrm{m}^{2}$ per hour on both the 3 - and $4-\mathrm{mm}$ $\mathrm{CD}$ membranes, was higher for the 3- than the 4-mm membranes (Figure 3). At the limiting flux, there was overlap in the required TMP as shown in Figure 3, with

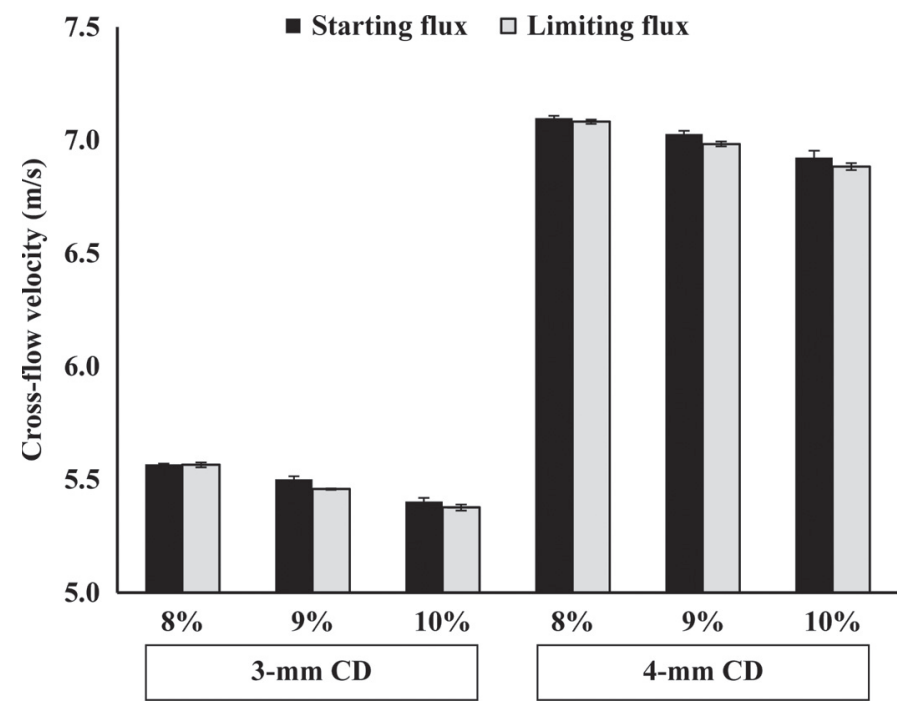

Figure 2. Mean $(\mathrm{n}=3)$ cross-flow velocity (calculated from the measured recirculation rate; with SD) at the starting and limiting flux for the 3- and 4-mm channel diameter (CD) membranes at 8, 9, and $10 \%$ recirculation loop target true protein (TP) concentration. a trend toward a higher TMP with the 3- compared with the 4-mm CD membranes.

Limiting Flux. The limiting flux for the target recirculation loop TP concentrations for both the 3- and 4-mm membranes are shown in Table 5. The limiting flux was a function of both recirculation loop TP concentration and CD (Table 4). At each TP concentration in the retentate recirculation loop, the limiting flux was higher $(P<0.05)$ on the 4 - than the 3 -mm membranes $(P<0.05$; Table 5$)$. The difference between the limiting fluxes explains the significant flux by TP and flux

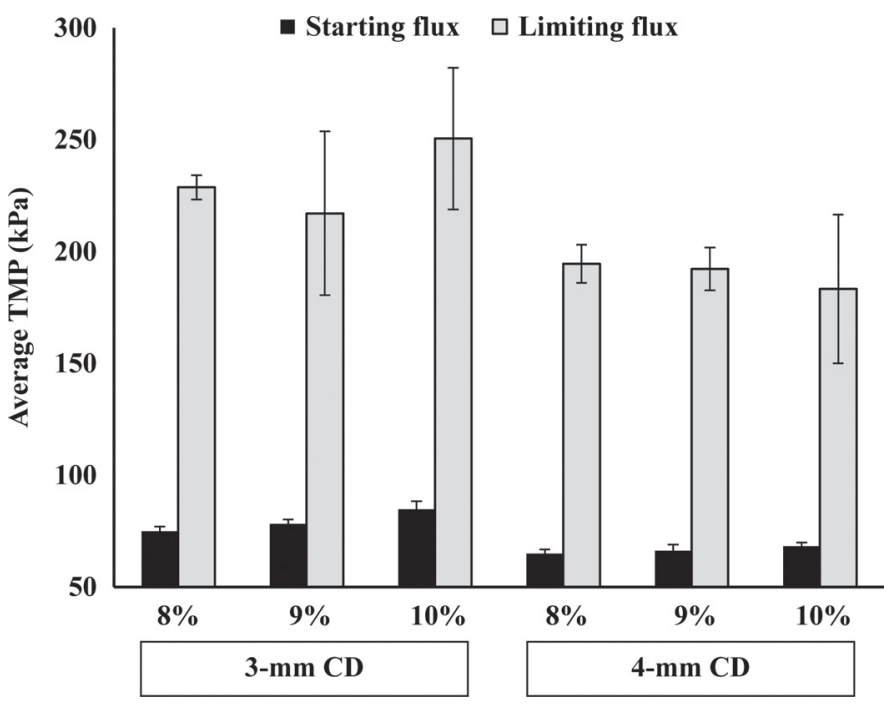

Figure 3. Mean $(\mathrm{n}=3)$ transmembrane pressure (TMP; with SD) at the starting and limiting flux for the 3 - and 4-mm channel diameter (CD) membranes at 8,9 , and $10 \%$ recirculation loop target true protein concentration. 
Table 5. Mean $(\mathrm{n}=3)$ limiting flux and permeate removal rate per module for the 3 -mm channel diameter (CD) membranes $\left(2.5 \mathrm{~m}^{2}\right)$ and the $4-\mathrm{mm} \mathrm{CD}$ membranes $\left(1.7 \mathrm{~m}^{2}\right)$ at 8,9 , and $10 \%$ recirculation loop target true protein $(\mathrm{TP})$ concentrations

\begin{tabular}{llccc}
\hline & & \multicolumn{3}{c}{ Target TP concentration } \\
\cline { 3 - 4 } $\mathrm{CD}$ & Variable & $8 \%$ & $9 \%$ & $10 \%$ \\
\hline $3 \mathrm{~mm}$ & Limiting flux $\left(\mathrm{kg} / \mathrm{m}^{2}\right.$ per hour) & $128^{\mathrm{b}}$ & $109^{\mathrm{b}}$ & $97^{\mathrm{b}}$ \\
$4 \mathrm{~mm}$ & Limiting flux $\left(\mathrm{kg} / \mathrm{m}^{2}\right.$ per hour) & $154^{\mathrm{a}}$ & $133^{\mathrm{a}}$ & $117^{\mathrm{a}}$ \\
& $\mathrm{SE}$ & 0.35 & 2.58 & 2.34 \\
$3 \mathrm{~mm}$ & $\mathrm{R}^{2}$ & $>0.99$ & 0.92 & 0.90 \\
$4 \mathrm{~mm}$ & Permeate removal rate $(\mathrm{kg} / \mathrm{h})$ & $320^{\mathrm{a}}$ & $273^{\mathrm{a}}$ & $242^{\mathrm{a}}$ \\
& Permeate removal rate $(\mathrm{kg} / \mathrm{h})$ & $262^{\mathrm{b}}$ & $227^{\mathrm{b}}$ & $198^{\mathrm{b}}$ \\
& $\mathrm{SE}$ & 0.75 & 6.40 & 4.03 \\
& $\mathrm{R}^{2}$ & $>0.99$ & 0.87 & 0.94 \\
\hline
\end{tabular}

${ }^{\mathrm{a}, \mathrm{b}}$ Means in the same column within limiting flux or permeate removal rate not sharing a common superscript are different for either the limiting flux or the permeate removal rate $(P<0.05)$.

by CD interactions for measured flux in Table 4. For all processing runs the starting flux was $55 \mathrm{~kg} / \mathrm{m}^{2}$ per hour, whereas the limiting flux depended both on the TP concentration and the CD. The difference in limiting flux between the 3- and 4-mm CD membranes was probably in part due to the difference in cross-flow velocity (Figure 2). To operate the $3-\mathrm{mm} \mathrm{CD} \mathrm{mem-}$ branes at the same cross-flow velocity as the 4-mm CD membranes would have required a much larger $\Delta \mathrm{P}$, and this would exceed the membrane manufacturers' design parameters for the membrane.

SP Removal. The SP removal decreased as flux increased for both the 3- and 4-mm CD membranes, as shown in Figure 4 and Table 4 . The SP removal factor was lower $(P<0.05)$ for the 3 - than the 4 -mm CD membranes (Figure 4 and Table 4 ). However, the decrease in SP removal with flux was similar among the 3- and 4-mm CD membranes (no significant interactions as shown in Table 4). The lower SP removal factor for the $3-\mathrm{mm}$ membranes may indicate that, even at the starting flux, there is increased membrane fouling due to lower cross-flow velocity that changed the rejection characteristics of the membrane.

\section{DISCUSSION}

\section{Effect of CD on Limiting Flux}

Hurt et al. (2015b) found that limiting flux could be predicted as a linear function of the Reynold's number (Equation 1) for the MF of diluted MPC85 on 4-mm CD membranes; however, CD was a constant in Hurt et al. (2015b). The measured viscosities, calculated densities, and Reynold's numbers for the 3-mm CD membranes are shown in Table 6. For the 3-mm CD membranes, the limiting flux predicted using Equation 2 was lower than the measured limiting flux; for example, at an $8 \%$ target TP, Equation 2 would predict a limiting flux of
$91 \mathrm{~kg} / \mathrm{m}^{2}$ per hour, which was lower than the measured limiting flux of $128 \pm 0.3 \mathrm{~kg} / \mathrm{m}^{2}$ per hour:

$$
\text { Limiting flux }=0.00764 \frac{\mathrm{kg}}{\mathrm{m}^{2} \mathrm{~h}} \times \text { Reynold's number. }
$$

The limiting fluxes as a function of Reynold's number are shown in Figure 5 for the 3- and 4-mm CD membranes. The Reynold's number does not explain the difference in limiting flux between the 3- and 4-mm CD membranes, as shown in Figure 5.

If CD was removed from the calculation of Reynold's number (Equation 1) and replaced by membrane length (1.02 $\mathrm{m}$ for both membranes) to maintain the dimensionless nature of the Reynold's number, a better cor-

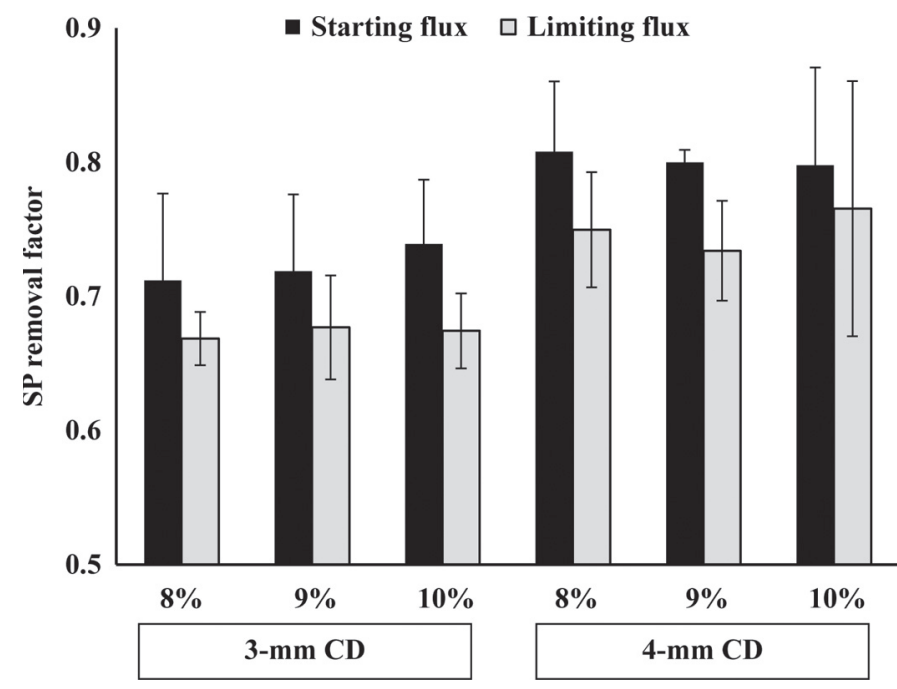

Figure 4. Mean $(\mathrm{n}=3)$ serum protein $(\mathrm{SP})$ removal factor at the starting and limiting flux (with SD) for the 3- and 4-mm channel diameter $(\mathrm{CD})$ membranes at 8,9 , and $10 \%$ recirculation loop target true protein concentration. 
relation for limiting flux was achieved (Figure 6), where limiting flux could be predicted using Equation 3:

$$
\begin{aligned}
& \text { Limiting flux }=3.07 \times 10^{-5} \frac{\mathrm{kg}}{\mathrm{m}^{2} \mathrm{~h}} \times \\
& \text { density } \times \text { cross-flow velocity } \times \text { membrane length }
\end{aligned}
$$

In Equation 3 the slope that provided the best fit to the observed limiting flux was determined by minimizing the sum of the squared difference between predicted and measured limiting flux. It appears that the limiting flux was well explained by the cross-flow velocity and retentate TP concentration (which affected density and viscosity) and not the $\mathrm{CD}$.

The limiting flux depends on the back transport of molecules away from the surface of the membrane, which is increased as shear rate at the membrane surface increases (Belfort et al., 1994). For laminar flow, the shear rate is proportional to the cross-flow velocity and inversely proportional to the CD (Belfort et al., 1994). As shown in Figure 5 for both the 3- and 4-mm CD membranes, the Reynold's number was $\gg 2,100$, indicating turbulent flow (Denn, 1980). It may be that
Table 6. Density, viscosity, and Reynold's number at the limiting flux for target true protein (TP) recirculation loop concentrations of 8,9 , and $10 \%$ on the $3-\mathrm{mm}$ channel diameter (CD) ceramic membranes

\begin{tabular}{lccc}
\hline $\begin{array}{l}\text { Target TP } \\
\text { concentration }\end{array}$ & $\begin{array}{c}\text { Viscosity }^{1} \\
\left(\mathrm{~Pa}^{*} \mathrm{~s}\right)\end{array}$ & $\begin{array}{c}\text { Density } \\
\left(\mathrm{kg} / \mathrm{m}^{3}\right)\end{array}$ & $\begin{array}{c}\text { Reynold's } \\
\text { number }^{3}\end{array}$ \\
\hline $8 \%$ & $0.0014^{\mathrm{c}}$ & $1,036^{\mathrm{c}}$ & $12,014^{\mathrm{a}}$ \\
$9 \%$ & $0.0017^{\mathrm{b}}$ & $1,040^{\mathrm{b}}$ & $10,162^{\mathrm{b}}$ \\
$10 \%$ & $0.0019^{\mathrm{a}}$ & $1,043^{\mathrm{a}}$ & $8,764^{\mathrm{c}}$ \\
$\mathrm{SE}$ & 0.00001 & 0.18 & 110 \\
$\mathrm{R}^{2}$ & $>0.99$ & $>0.99$ & 0.99 \\
\hline
\end{tabular}

${ }^{\mathrm{a}-\mathrm{c}}$ Means in the same column not sharing a common superscript are different $(P<0.05)$.

${ }^{1}$ Viscosity measured at $50^{\circ} \mathrm{C}$.

${ }^{2}$ Density calculated using equation of Stepp and Smith (1991): [Density $=1,034.72-0.39 \times$ temperature $\left.\left({ }^{\circ} \mathrm{C}\right)+1.69 \times \mathrm{TN}+0.10 \times \mathrm{TN}^{2}\right]$. $\mathrm{TN}(\%)=$ total nitrogen $\times 6.38$.

${ }^{3}$ Reynold's number calculated as follows: density $\left(\mathrm{kg} / \mathrm{m}^{3}\right) \times$ cross-flow velocity $(\mathrm{m} / \mathrm{s}) \times \mathrm{CD}(\mathrm{m}) /$ viscosity $(\mathrm{Pa} \times \mathrm{s})$.

$\mathrm{CD}$ did not have a large effect on the shear rate near the wall because the flow was turbulent for both CD. However, in our work, cross-flow velocity was not an independent variable and was a function of both CD and target TP concentration (Figure 2); thus, additional research would be required to verify whether or not CD had an independent effect on limiting flux.

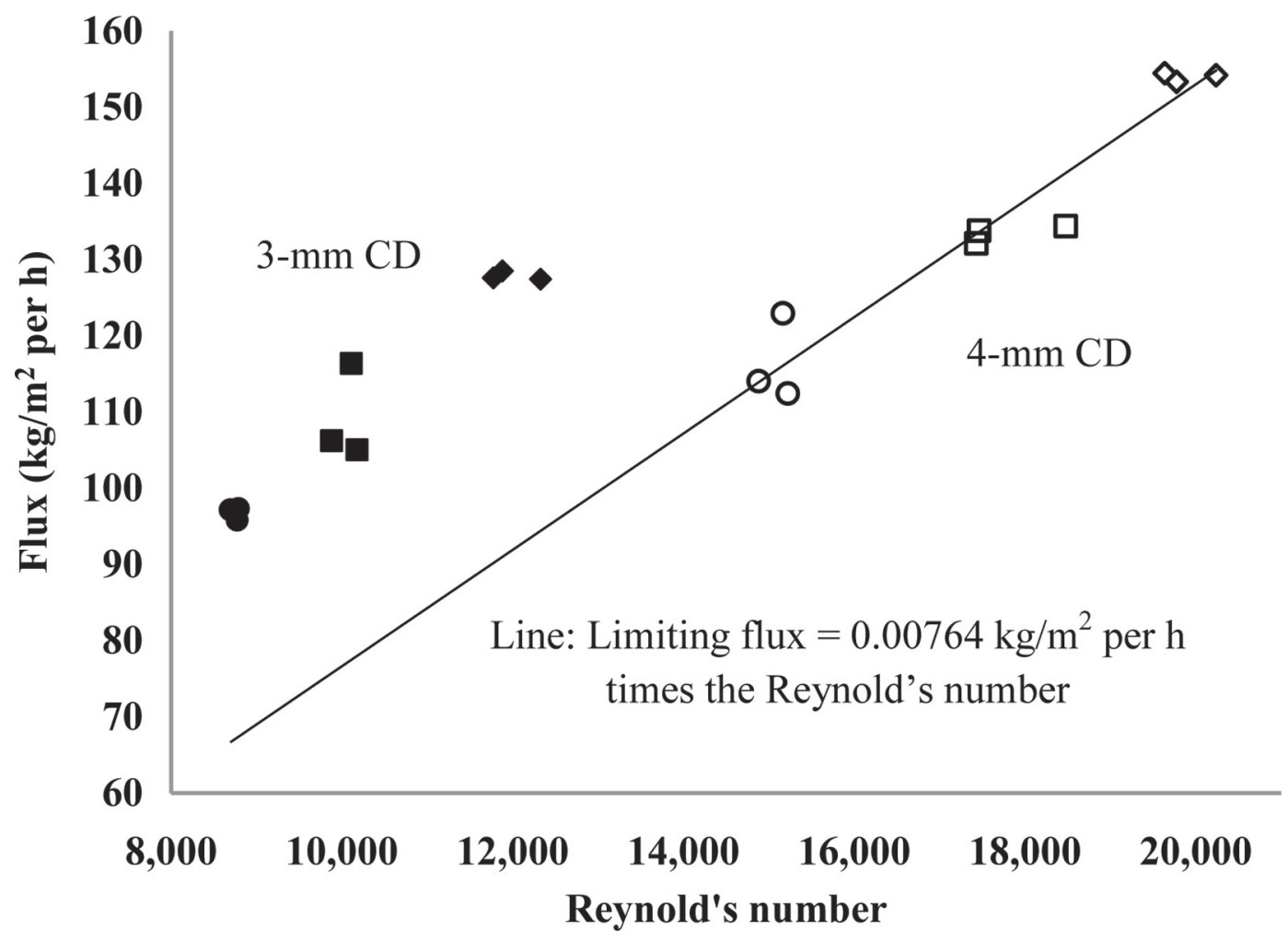

Figure 5. Limiting flux as a function of Reynold's number for 4-mm channel diameter (CD) membranes at $8(\diamond), 9(\square)$, and $10 \%(\bigcirc)$ recirculation loop target true protein (TP) concentration and the 3-mm CD membranes at $8(\bullet), 9(\boldsymbol{\square})$, and $10 \%(\bullet)$ recirculation loop target TP concentration. 


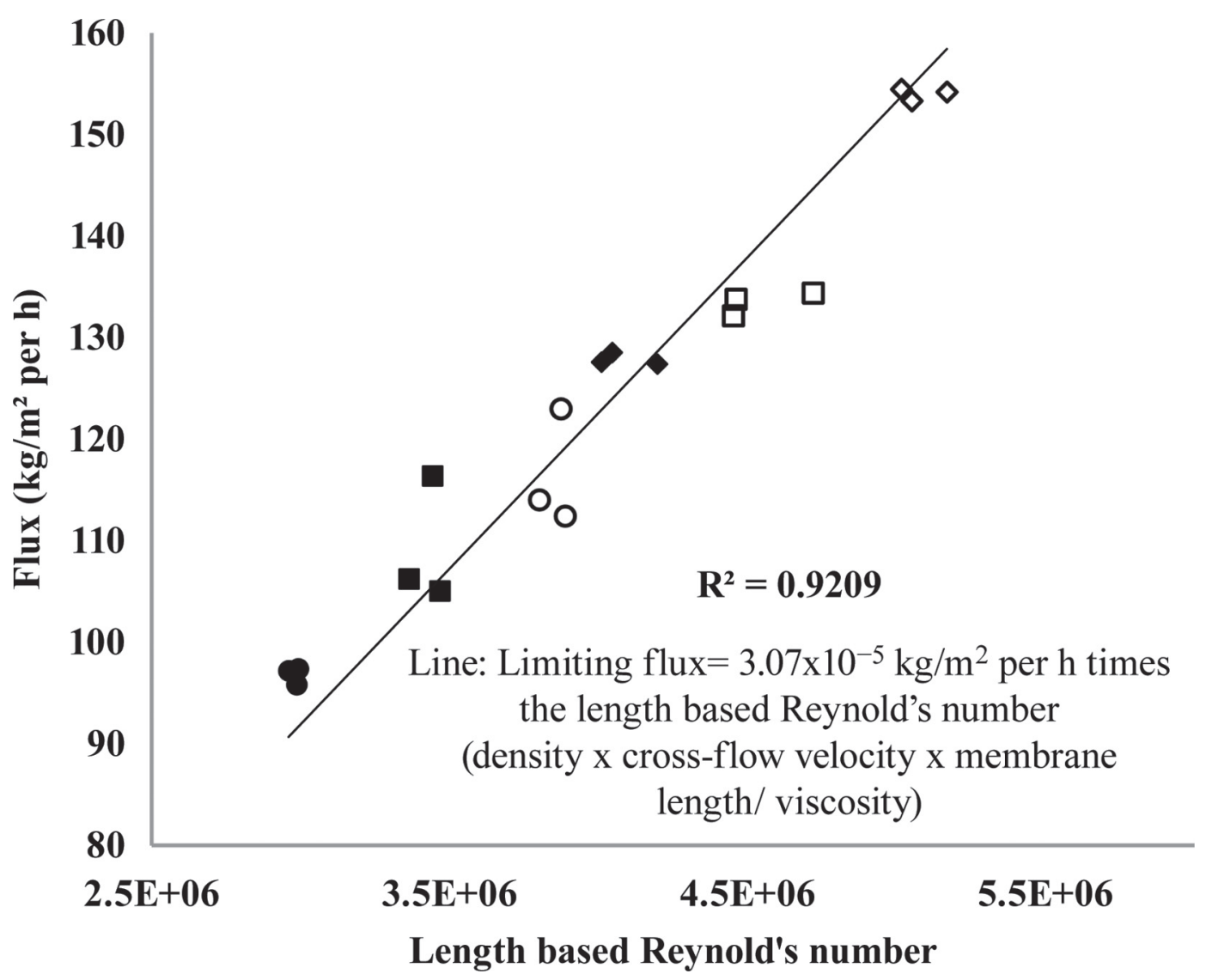

Figure 6. Limiting flux as a function of length dependent Reynold's number for 4-mm channel diameter (CD) membranes at $8(\diamond), 9(\square)$, and $10 \%(\bigcirc)$ recirculation loop protein concentration and the 3-mm CD membranes at $8(\bullet), 9(\square)$, and $10 \%(\bullet)$ recirculation loop true protein (TP) concentration.

\section{Sustainable Flux}

The sustainable flux is a flux that can be maintained for extended periods of time and where the rate of membrane fouling is slow (Bacchin et al., 2006). The flux versus TMP profiles for both the 3 - and 4-mm CD membranes are shown in Figure 7. The flux versus TMP curves begin to level off after a TMP of approximately $150 \mathrm{kPa}$, indicating that membrane fouling was increasing at TMP higher than $150 \mathrm{kPa}$ (Figure 7).

The relationship between TMP and limiting and sustainable flux in Figure 7 is obscured by the difference in the limiting flux among the CD and target recirculation loop TP concentrations. To better explore the relationship between TMP and flux, flux was scaled (100 times measured flux divided by limiting flux) as shown in Figure 8. Regardless of the CD or recirculation loop protein concentration, it appears that a TMP corresponds to a percentage of the limiting flux. A TMP of approximately $150 \mathrm{kPa}$ corresponded to roughly 80 to $85 \%$ of the limiting flux, independent of the target TP concentration or membrane CD. The concept that a sustainable flux would be a fraction of the limiting flux is consistent with a report by Bacchin (2004), indicating that critical flux was a fraction of the limiting flux. Although, it would need to be validated, Figures 7 and 8 suggest that $150 \mathrm{kPa}$ may be a practical TMP that corresponds to a sustainable flux for both the 3- and 4-mm CD membranes at a variety of recirculation loop protein concentrations.

\section{Factors to Consider in Choice of Membranes and Operating Conditions}

Recirculation Loop Protein Concentration. The choice of recirculation loop TP concentration will affect both the amount of permeate that will need to be removed and the sustainable flux that the system can operate at. To produce an MCC with a specific reduction in $\mathrm{SP}$ or lactose, increasing the recirculation loop TP concentration will decrease the amount of MF permeate that has to be removed (Hurt and Barbano, 2015a); however, as shown in the present study, increas- 


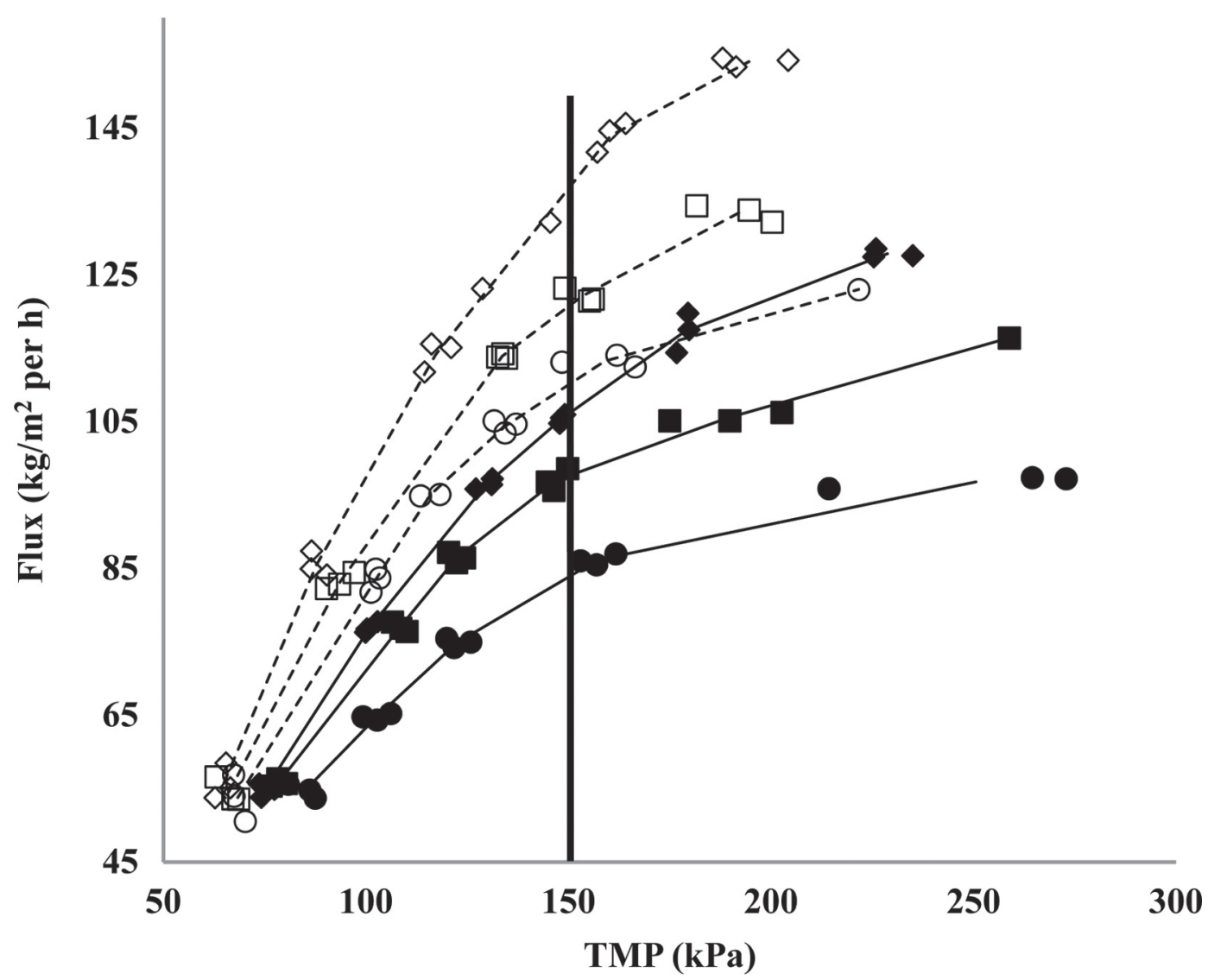

Figure 7. Flux versus transmembrane pressure (TMP) profiles for 4-mm channel diameter (CD) membranes at $8(\diamond), 9(\square)$, and $10 \%(\bigcirc)$ recirculation loop protein concentration and the 3-mm CD membranes at $8(\diamond), 9(\boldsymbol{\square})$, and $10 \%(\bullet)$ recirculation loop true protein (TP) concentration.

ing the recirculation TP concentration will decrease the sustainable and limiting flux (Table 5).

$\boldsymbol{C D}$. Increasing $\mathrm{CD}$ increased $(P<0.05)$ both the limiting flux (Tables 4 and 5) and the SP removal (Figure 4 and Table 4). Because of the lower SP removal factor, to remove the same amount of SP with the 3 -mm membranes more permeate would have to be removed (either by adding more diafiltration water or increasing the $\mathrm{CF}$ ) than with the 4-mm CD membranes. Even though the limiting fluxes were lower for the 3-mm CD membranes, as shown in Table 5, the permeate removal rate per stainless steel module was larger for the 3-mm CD membranes because of the increased surface area per module. The surface area per module could also affect process operation. At startup, water has to be flushed from the system, and the concentration of $\mathrm{TP}$ in the recirculation loop has to be increased to the target concentration by the removal of permeate. A higher removal rate per module would reduce the time required to reach steady state, but the risk of going too high in protein too fast and fouling out the system would increase as well. If an increase in retentate recirculation loop TP concentration (above the target $\mathrm{TP}$ concentration) caused the membranes to foul to the extent that caused SP passage and flux to decrease to an unacceptable level, then termination of the run and a full clean of the system would be required. The potential for variation in the recirculation loop TP concentrations should be factored into the target recirculation loop TP concentration and flux for the process, to avoid short and variable length production runs. This may be more of a concern for a system with 3- rather than 4-mm CD membranes because of the greater membrane area per module.

Number of Recirculation Loops. Each recirculation loop in a MF process would require a recirculation pump, valves, and control systems regardless of the membrane area per loop. If each module requires a 220 $\mathrm{kPa}$ pressure drop, the number of modules per recirculation loop will also be constrained by the ability of the recirculation pump to provide the necessary pressure drop. In designing a multistage ceramic MF system, 


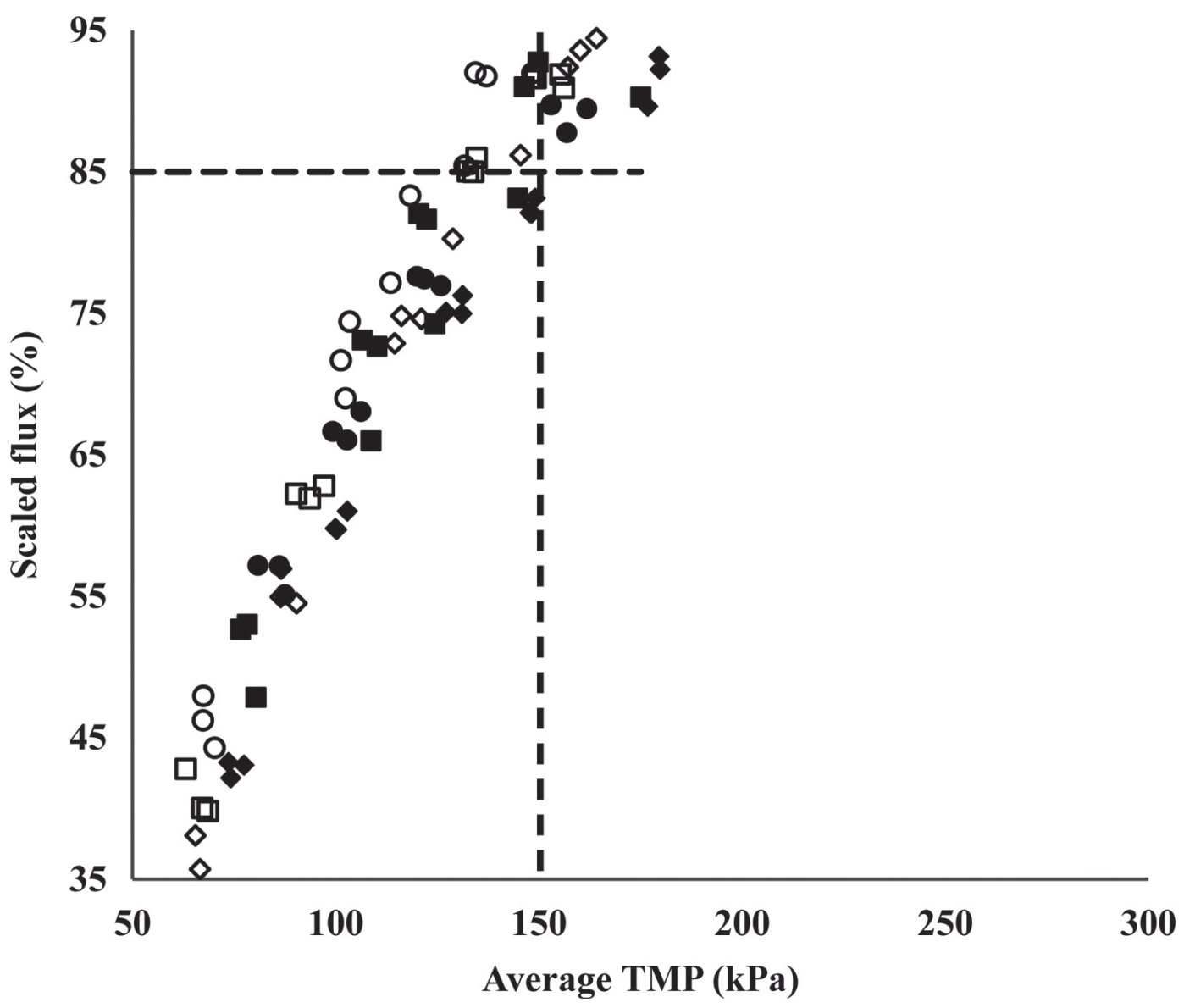

Figure 8. Scaled flux as a function of transmembrane pressure (TMP) for the 4-mm channel diameter (CD) membranes at $8(\diamond), 9(\square)$, and $10 \%(\bigcirc)$ recirculation loop protein concentration and the 3 -mm CD membranes at $8(\bullet), 9(\boldsymbol{\square})$, and $10 \%(\bullet)$ recirculation loop protein concentration.

minimization of the number of recirculation loops or modules may be more important than the minimization of membrane area from the perspective the hardware cost and daily operational expense. Increasing the number of recirculation loops will also increase the dead volume of the system. As the dead volume of the MF process increases, the potential loss of product at both the start and end of the run increases. At start-up, as water is flushed from the system, the retentate TP concentrations will be below their target concentrations and a decision would have to be made about where to send the retentate (i.e., to the drain, recycle to feed tank). At the end of the run, all recirculation loops would be filled with retentate, some of which may be recovered in a flush step. Operational procedures at both the start and end of the run would need to be implemented to minimize TP loss.

Optimal System Design. The optimal system design (number of recirculation loops, recirculation loop $\mathrm{TP}$ concentration, and membrane CD) will depend on the desired production rate and target composition for the final MCC. The target MCC production rate would affect the number of recirculation loops required. For a very small production rate 1 recirculation loop (stage) might suffice, but as the target production rate increases the number of recirculation loops would have to increase (because each recirculation loop can only accommodate so much membrane area). The target final MCC composition with respect to percentage of total SP removal and TP concentration would also affect the optimal system design. For example, if MCC production rate and low final TP concentration in the MCC was more important than total percentage of $\mathrm{SP}$ removal, then the 3-mm CD membranes with their larger permeate removal per module (but lower SP removal factor) would probably be optimal. Additionally, the final MCC TP concentration could affect the choice of recirculation loop TP concentration and membrane CD. At higher TP concentration, more open-flow CD would reduce risk of fouling early in the processing run. 


\section{CONCLUSIONS}

For the 3-mm CD membranes, the limiting flux was $128 \pm 0.3,109 \pm 4$, and $97 \pm 0.5 \mathrm{~kg} / \mathrm{m}^{2}$ per hour at recirculation loop TP concentrations of $8.1 \pm 0.07,9.2$ \pm 0.04 , and $10.2 \pm 0.03 \%$, respectively. For the 3 -mm CD membranes, increasing the flux from the starting to the limiting flux decreased the SP removal factor from $0.72 \pm 0.02$ to $0.67 \pm 0.01$; however, no difference in SP removal factor among the target recirculation loop TP concentrations was detected. The limiting flux at each recirculation loop target TP concentration was lower for the 3-mm compared with the 4-mm CD membranes. The differences in limiting fluxes between the 3- and 4-mm CD membranes were explained in part by the difference in cross-flow velocity $(5.5 \pm 0.03$ and $7.0 \pm$ $0.03 \mathrm{~m} / \mathrm{s}$ for the 3 - and $4-\mathrm{mm}$ CD membranes, respectively). The SP removal factor was also lower for the 3- compared with the 4-mm CD membranes, indicating that more membrane fouling may have occurred in the 3- versus 4-mm CD membranes.

\section{ACKNOWLEDGMENTS}

The authors thank the Northeast Dairy Foods Research Center (Ithaca, NY) and New York State Milk Production Board (Albany, NY) for partial funding of this research. The authors also thank O-AT-KA Milk Products Cooperative (Batavia, NY) and Pall Corporation (Cortland, NY) for their support of this research. Additionally, the technical assistance of Michelle Bilotta, Sara Bova, and Chassidy Coon from the Department of Food Science at Cornell University was greatly appreciated.

\section{REFERENCES}

Adams, M. C., and D. M. Barbano. 2013. Serum protein removal from skim milk with a 3 -stage $3 \mathrm{X}$ ceramic isoflux membrane process at $50^{\circ}$ C. J. Dairy Sci. 96:2020-2034.
AOAC International. 2000. Official Methods of Analysis. 17th ed. AOAC International, Gaithersburg, MD.

Bacchin, P. 2004. A possible link between critical and limiting flux for colloidal systems: Consideration of critical deposit formation along the membrane. J. Membr. Sci. 228:237-241.

Bacchin, P., P. Aimar, and R. W. Field. 2006. Critical and sustainable fluxes: Theory, experiments and applications. J. Membr. Sci. 281:42-69.

Belfort, G., R. H. Davis, and A. L. Zydney. 1994. The behavior of suspensions and macromolecular solutions in crossflow microfiltration. J. Membr. Sci. 96:1-58.

Cheryan, M. 1998. Ultrafiltration and Microfiltration Handbook. Technomic Publishing Company Inc., Lancaster, PA.

Denn, M. M. 1980. Process and Fluid Mechanics. Prentice Hall PTR. Upper Saddle River, NJ.

Fauquant, J., J. -L. Maubois, and A. Pierre. 1988. Microfiltration du lait sur membrane minerale. Tech. Lait. 1028:21-23.

Garcera, D. and E. Toujas. 2002. Graded permeability macroporous support for crossflow filtration. Societe Ceramiques Techniques, assignee. USPat. No. 6,375,014B1.

Grangeon, A., P. Lescoche, T. Fleischmann and B. Ruschel. 2002. Cross-flow filter membrane and method of manufacturing it. Technologies Avancees and Membranes Industrielles, assignee. USPat. No. 6,499,606 B1.

Holm, S., R. Malmberg, and K. Svensson, inventors. 1990. Arrangement in membrane filter. Alfa-Laval AB, assignee. US Pat. No. $4,906,362$.

Hurt, E. E., M. C. Adams, and D. M. Barbano. 2015b. Microfiltration: Effect of retentate protein concentration on limiting flux and serum protein removal with $4 \mathrm{~mm}$ channel diameter ceramic microfiltration membranes. J. Dairy Sci. 98:2234-2245.

Hurt, E. E, and D. M. Barbano. 2015a. Factors that influence the membrane area of a multi-stage microfiltration process required to produce a micellar casein concentrate. J. Dairy Sci. 98:2222-2234.

Lynch, J. M., D. M. Barbano, and J. R. Fleming. 2007. Determination of the lactose content of fluid milk by spectrophotometric enzymatic analysis using weight additions and path length adjustment. J. AOAC Int. 90:196-216.

Samuelsson, G., P. Dejmek, G. Tragardh, and M. Paulsson. 1997. Minimizing whey protein retention in cross-flow microfiltration of skim milk. Int. Dairy J. 7:237-242.

Sondhi, R., R. Bhave, and G. Jung. 2003. Applications and benefits of ceramic membranes. Membr. Technol. 2003:5-8.

Stepp, B. L., and D. E. Smith. 1991. Effect of concentration and temperature on the density and viscosity of skim milk retentates. Milchwissenschaft 46:484-487.

Zulewska, J., M. Newbold, and D. M. Barbano. 2009. Efficiency of serum protein removal from skim milk with ceramic and polymeric membranes at $50^{\circ} \mathrm{C}$. J. Dairy Sci. 92:1361-1377. 